\title{
Improvements That are Applicable in the Automation System to Increase CH4 Ratio in Co-Fermentation Plants
}

\author{
Mustafa KARAGÖZ ${ }^{1}$, Burak ÇİTÇí ${ }^{1}$, Nuri TUNÇ $^{2}$, Emrah DENIZ $^{3}$ \\ 1.TOBB Tech. Sciences Vocational School, Karabuk University, Turkey, E-mail: mustafakaragoz@karabuk.edu.tr, \\ E-mail: burakciftci@karabuk.edu.tr \\ 2.Graduate School of Natural \& Applied Sciences, Department of Mechanical Engineering, Karabuk University, \\ Turkey, E-mail: tunckar.nt@gmail.com \\ 2.Faculty of Engineering, Department of Mechanical Engineering, Karabuk University, Turkey, E-mail: \\ edeniz@karabuk.edu.tr
}

\begin{abstract}
Increasing the rate of $\mathrm{CH}_{4}$ in thebiogas is very important in terms of the efficient evaluation of the resources as well as the efficient fulfillment of energy demand. One of the methods "'that can be used for this purpose, also known as co-fermentation, is to process different organic wastes, at a certain rate. Although the fermentation of organic waste mixtures in the specified amounts contributes to the increase of the $\mathrm{CH}_{4}$ ratio in the biogas content, it may cause the halt of biogas production in excess of the amounts determined in the organic waste mixture ratios. In this study, improvements in biogas plant automation are presented and proposed to prevent digester failure in plants producing biogas with co-fermentation.
\end{abstract}

Keywords - Biogas production, Programmable logic control, Biogas plant automation, Co- fermentation, İncreased methane content

\section{Introduction}

Nowadays, in parallel with the evolving living standards, increasing the amount of energy consumption and finding alternatives to fossil-based energy sources have significantly increased the interest in renewable and also sustainable energy resources. One of the renewable and sustainable energy sources, biogas production under anaerobic conditions (biometanation), in other words, production of methane $\left(\mathrm{CH}_{4}\right)$ from organic wastes, can be considered among the prominent sources of energy, due to the high potential of energy production as well as being considered as a helping factor in eliminating environmental problems. The biogas content produced by anaerobic fermentation includes a small amount of $\mathrm{NH}_{3}$ (80-100 ppm), $\mathrm{H}_{2} \mathrm{~S}$ (1000$3000 \mathrm{ppm})$ and hydrocarbons $(<100 \mathrm{ppm})$ and 55-70\% $\mathrm{CH}_{4}, 30-45 \% \mathrm{CO}_{2}[1,2]$. The lower thermal value of the biogas increases due to the increase in the methane content in the biogas content [3]. The Biogas has a Lower heating value of $20.5 \mathrm{MJ} / \mathrm{m} 3$ with a methane content of $57 \%$, while the biogas with a methane content of $51 \%$ has a Lower heating value of $18.6 \mathrm{MJ} /$ $\mathrm{m} 3$ at $1 \mathrm{~atm}$ and $15^{\circ} \mathrm{C}$. Bigogaz can be used efficiently both in electricity generation (as fuel in generators) and in households for heating and cooking [4]. Anaerobic fermentation can be divided into four biological processes: hydrolysis, acidogenesis, acetogenesis, and methanogenesis [5,6]. Aneorabic fermentation is a complex biological process. In this process fermentation is influenced by both physical factors such as retention time, temperature, mixing, loading rate and chemical factors that are influencing the environment such as $\mathrm{C} / \mathrm{N}, \mathrm{pH}$, alkalinity, toxic substances [7]. Organic wastes used in fermentation are an important factor in biogas production. Each organic material has the potential to produce a certain amount of biogas when appropriate conditions are met. The co-fermentation of different raw materials changes the biogas production potential and improves process efficiency according to mono-digestion (single 
organic waste fermentation) [8]. Kim at al. has co-fermented spent coffee ground with sea lettuce and food waste due to the fact that the spent coffee ground is prone to fermentation failure when subjected to fermentation process alone. In addition, they determined the optimum ratio of waste used in co-fermentation for high methane yield [9]. In their study, al-Mashad and Zhang reported that co-fermentation of food waste and dairy farm manure gave higher biogas yield results than dairy farm manure fermentation only by itself [10]. There are many research studies indicating the benefits of co-fermentation of different organic wastes [11-15]. In the literature, many studies related to co-fermentation of animal manure or wastewater with agricultural food can be found. In these studies co-fermentation was performed by adding two or three raw materials into the fermentor [16-22].

Co-fermentation can improve fermentation performance by providing stability of fermentation, adjustment of carbon / nutrient ratio, remedying the trace-element deficiency, reduction of inhibitory content, increasing the buffering capacity $[9,23]$. Therefore, the selection of the appropriate raw materials to be fermented together and the determination of the optimum mixing ratios are very important for successful fermentation [9]. Although the fermentation of organic waste mixtures in the specified amounts contributes to the increase of the $\mathrm{CH}_{4}$ ratio in the biogas content, it may cause the biogas production to halt in excess of the amounts determined in the organic waste mixture ratios. Although the fermentation of organic waste mixtures in the specified amounts contributes to the increase of the $\mathrm{CH}_{4}$ ratio in the biogas content, it may cause the halt of biogas production in excess of the amounts determined in the organic waste mixture ratios.

In this study, in order to prevent fermentation failure and to increase the methane yield, a biogas plant automation was proposed in which pneumatic actuator, solenoid valve, flowmeter, lobe pump was used, to the plants producing biogas with co-fermentation.

\section{Proposed system}

Facilities with anearobic fermentation process are generally divided into four processes, although there are facilities in different operating styles. These are process 1 fermenters; process 2 production of biogas; process 3 evaluation of biogas; and process 4 evaluation of fermentation wastes. Figure 1 shows the general process for biogas production [24]. 


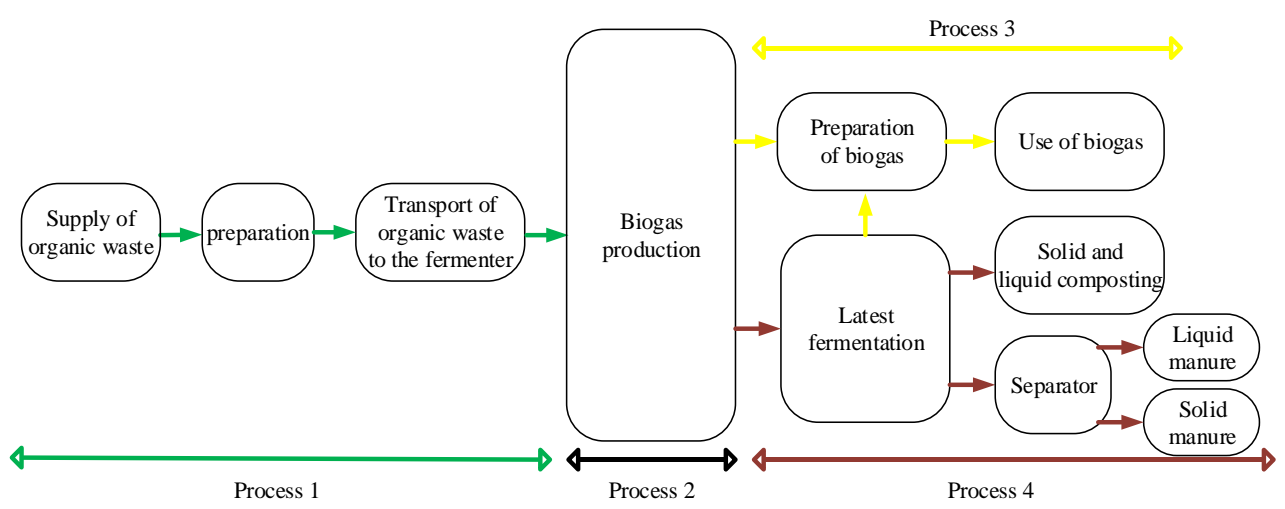

Figure 1. General process for biogas production

The $1^{\text {st }}$ process consists of the procurement of organic raw material, fragmentation and crushing of the raw material if necessary, and the addition of organic raw material to the fermenter. Generally, the transportation of the raw material in the plant and the feed of the fermentor is carried out by machines such as loader or bulldozer. $2^{\text {nd }}$ process is the production of biogas in the fermenter. The $3^{\text {rd }}$ process consists of the use of the produced biogas in cogeneration or trigeneration systems. The $4^{\text {th }}$ process is related to the processing of the fertilizer after fermentation.

Traditionally, in biogas plants that work with different wastes, work of transportation of organic wastes to the mixing tank for the co-fermentation, is carried out by a loader or similar heavy duty vehicle. If optimum mixing ratios cannot be achieved in the mixing tank, the methane production rate decreases.

In the proposed system, optimum mixing ratios will be obtained by ensuring that the organic raw material is sent automatically to the mixing tank at the determined rate from the tanks made for the different mixtures. Thus, the increase in methane production can be realized at maximum level. Figure 2 shows a diagram of the proposed system. 


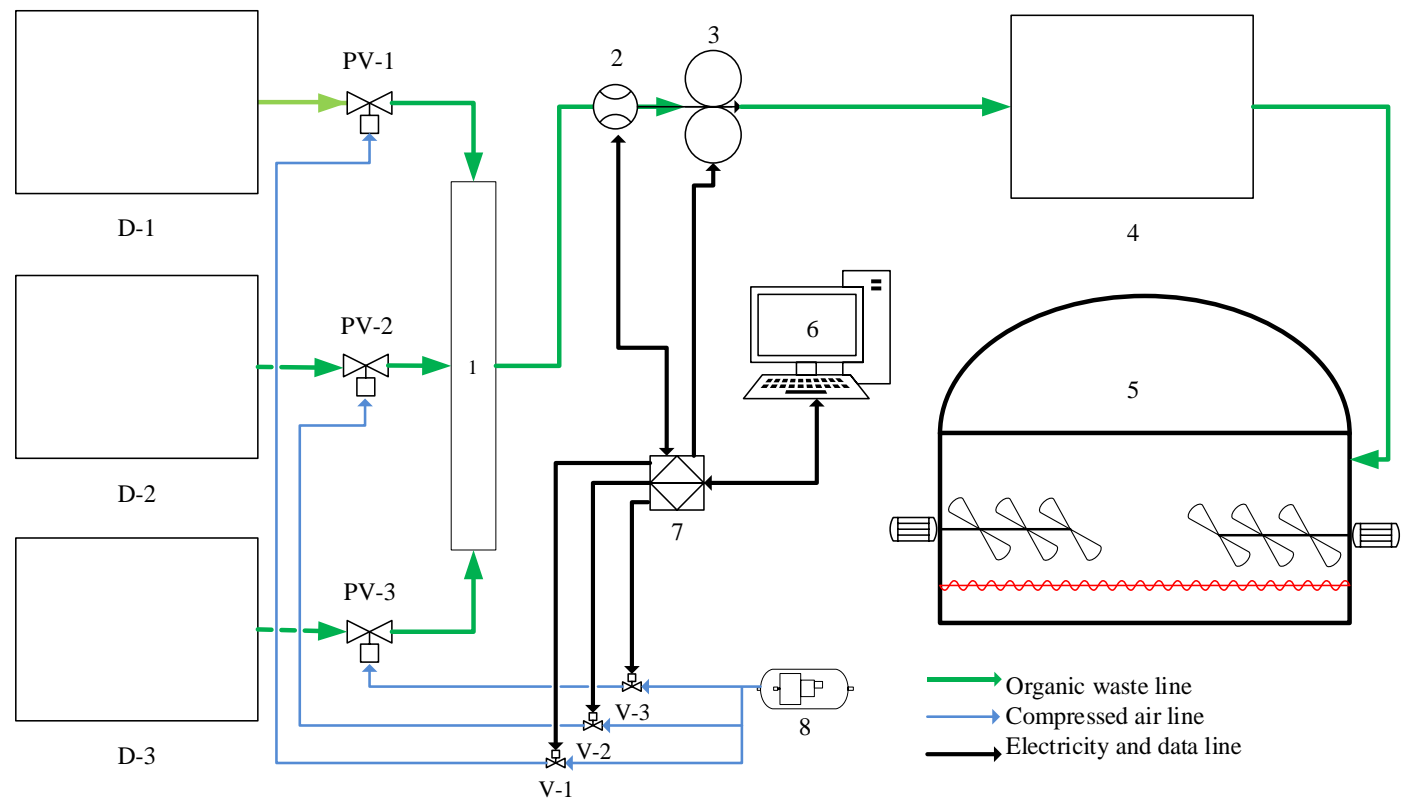

\begin{tabular}{|c|c|r|c|}
\hline D & Organic waste storage & 4 & Mixing tank \\
\hline PV & Knife gate valve with pneumatic actuator & 5 & Fermenter \\
\hline V & Convertible solenoid valves & 6 & Computer \\
\hline 1 & Organic waste collector & 7 & Programmable logic controller \\
\hline 2 & Flowmeter & 8 & Air compressor \\
\hline 3 & Lobe pump & & \\
\hline
\end{tabular}

Figure 2. Schematic view of raw material transfer system,

The system is designed to pump the set values to the mixer. The amount of waste to be sent to the mixer from the D-1, D-2 and D-3 organic waste tanks is entered from the scada screen. PLC triggers the pump and the convertible solenoid valve for organic waste delivery from the D1 organic waste tank to the mixer, the compressed air through the V-1 valve opens the PV-1 valve and the organic waste transfer from the D-1 to the mixing tank takes place. The flow meter on the line sends the passed amount as a signal to the PLC. Valves and pumps close when the set value is reached. When the value set in the Scada display is reached, the valves and pumps are switched off. The same process is repeated in organic wastes stored in D-2 and D-3 tanks, thus ensuring optimum mixing ratio to the Mixing tank and so the optimum mixing ratio is provided to the Mixing tank.

\section{Conclusion}

Increasing the rate of $\mathrm{CH}_{4}$ in thebiogas is very important in terms of the efficient evaluation of the resources as well as the efficient fulfillment of energy demand. One of the methods that can be used for this purpose, also known as co-fermentation, is to process different organic wastes, at a certain rate. Although the fermentation of organic waste mixtures in the specified amounts contributes to the increase of the $\mathrm{CH}_{4}$ ratio in the biogas content, it may cause the halt of biogas production in excess of the amounts determined in the organic waste mixture ratios. Therefore, the selection of the appropriate raw materials to be fermented together and the determination of the optimum mixing ratios are very important for a successful fermentation. In 
this study, improvements in biogas plant automation are presented and proposed to prevent digester failure in plants producing biogas with co-fermentation.

In this study, it is suggested to the plants which are producing biogas with co-fermentation, make improvements in automation by adding organic waste storage, knife gate valve with pneumatic actuator, organic waste collector, flowmeter, lobe pump, to prevent digester failure and to achieve maximum methane yield.

\section{References}

[1] J. Xuan, M. Leung, D. Leung, and M. Ni, "A review of biomass-derived fuel processors for fuel cell systems” Renew. Sustain. Energy Rev., 13, pp. 1301-1313, 2009.

[2] M. Karagöz, N. Tunç, B. Çiftçi, İ. Ekmekçi and E. Deniz, "Experimental Investigation on The Usability of Granulated Furnace Slag in Biogas Purification Processes" Third International Iron and Steel Symposium, Karabuk, 2017, pp. 332-335.

[3] Gomez Montoya J.P.G., et al., "Spark ignition engine performance and emissions in a high compression engine using biogas and methane mixtures without knock occurrence", Thermal Science, 19, pp. 1919-30, 2015.

[4] M. Karagöz, N. Tunç, B. Çiftçi, and E. Deniz, "Experimental Investıgation of the Usability of Ponza Stone and Blast Furnace Slag Mixture in Biogas Purification Processes" II. International Symposium on Multidisciplinary Studies, Rome, 2017,pp. 109-121.

[5] J.L. Chen, R. Ortiz, T.W.J. Steele, D.C. Stuckey, "Toxicants inhibiting anaerobic digestion: a review", Biotechnol Adv., 32, pp. 1523-34, 2014.

[6] E. Abdelsalam, M. Samer, M.A. Abdel-Hadi, H.E. Hassan, Y. Badr, "Influence of laser irradiation on rumen fluid for biogas production from dairy manure", Energy, 163 pp. 404415, 2018.

[7] M. Demuynck, J. Nyns, W. Palz, "Biogas Plants in Europe, Energy from Biomass Series", 6. D. Reidel Publishing Company, Boston, USA,1984.

[8] S, Mehariya, A, K, Patel, P, K, Obulisamy, E, Punniyakotti, J, W, C, Wonga, "Codigestion of food waste and sewage sludge for methane production: Current status and perspective", Bioresource Technology, Vol: 265, pp. 519-531, 2018.

[9] J. Kim, G. Baek, J. Kim, C. Lee, "Energy production from different organic wastes by anaerobic codigestion: Maximizing methane yield versus maximizing synergistic effect", Renewable Energy, 136, pp., 683-690, 2019.

[10] H, El-Mashad, R, Zhang, "Biogas production from co-digestion of dairy manure and food waste” Bioresour. Technol., 101 (11), pp. 4021-4028, 2010.

[11] C, Zhang, G, Xiao, L, Peng, H, Su, T, "TanThe anaerobic co-digestion of food waste and cattle manure”, Bioresour. Technol., 129, pp, 170-176, 2013.

[12] E, Maranon, L, Castrillon, G, Quiroga, Y, Fernandez-Nava, L, Gomez, M,M, Garcia, “Codigestion of cattle manure with food waste and sludge to increase biogas production" Waste Manage., 32 pp. 1821-1825, 2012.

[13] F,J, Callaghan, D,A,J, Wase, K, Thayanity, C,F, Forster, "Continuous co-digestion of cattle slurry with fruit and vegetable wastes and chicken manure” Biomass Bioenerg., 22, pp. 71-77, 2002. 
[14] J, De Vrieze, L, De Lathouwer, W, Verstraete, N, Boon, "High-rate iron-rich activated sludge as stabilizing agent for the anaerobic digestion of kitchen waste" Water Res., 47 (11), pp. 3732-3741, 2013.

[15] I,S, Kim, M,H, Hwang, N,J, Jang, S,H, Hyun, S, T, Lee,"Effect of low pH on the activity of hydrogen utilizing methanogen in bio-hydrogen process” Int. J. Hydrogen Energ. 29 (11) pp. 1133-1140, 2004.

[16] J.H. El Achkar, T. Lendormi, Z. Hobaika, D. Salameh, N. Louka, R. G.Maroun, J.-L. Lanoisellé, "Anaerobic digestion of grape pomace: biochemical characterization of the fractions and methane production in batch and continuous digesters", Sustain. Energy Technol. Assess., 29, pp. 44-4, 2018.

[17] M. Guerini-Filho, M. Lumi, C. Hasan, M. Marder, L.C.S. Leite, O. Konrad "Energy recovery from wine sector wastes: a study about the biogas generation potential in a vineyard from Rio Grande do Sul, Brazil", Sustain. Energy Technol. Assess., 29, pp. 4449, 2018.

[18] D. Patowary, D.C. Baruah "Effect of combined chemical and thermal pretreatments on biogas production from lignocellulosic biomasses", Ind. Crops Prod., 124, pp. 735-746, 2018.

[19] D.R. Sousa Lima, O.F. Herrera Adarme, B.E. Lobo Baêta, L.V.Alves Gurgel, S.F. de Aquino "Influence of diff ;erent thermal pretreatments and inoculum selection on the biomethanation of sugarcane bagasse by solid-state anaerobic digestion: a kinetic analysis" Ind. Crops Prod., 111, pp. 684-693, 2018.

[20] V. Riggio, E. Comino, M. Rosso, "Energy production from anaerobic co-digestion processing of cow slurry, olive pomace and apple pulp", Renew. Energy, 83, pp. 10431049, 2015.

[21] B.A. Aylin-Alagöz, O. Yenigün, A. Erdinçler, "Enhancement of anaerobic digestion efficiency of wastewater sludge and olive waste: synergistic effect of co-digestion and ultrasonic/microwave sludge pre-treatment", Waste Manag., 46, pp. 182-188, 2015.

[22] A. I. Parralejo, L. Royano J. González, J. F.González, "Small scale biogas production with animal excrement and agricultural residues", Industrial Crops and Products, 131, pp., 307314, 2019.

[23] J. Kim, H. Kim, G. Baek, C. Lee, "Anaerobic co-digestion of spent coffee grounds with different waste feedstocks for biogas production", Waste Manag., 60, pp., 322-328, 2017.

[24] D. Kaya, ve H. Öztürk, "Biogas technology”, Umuttepe Publications, İzmit, 2012. 